NASA Technical Memorandum 106820

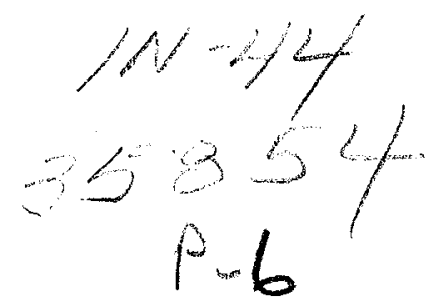

\title{
Pulsed Laser Illumination of Photovoltaic Cells
}

Jane A. Yater

National Aeronautics and Space Administration

Lewis Research Center

Cleveland, Ohio

Roland A. Lowe

Kent State University

Kent, Ohio

Phillip P. Jenkins and Geoffrey A. Landis

NYMA, Inc.

Engineering Services Division

Brook Park, Ohio

Prepared for the

First World Conference on Photovoltaic Energy Conversion cosponsored by the IEEE, PVSEC-Japan, PVSEC-Europe Waikoloa, Hawaii, December 5-9, 1994

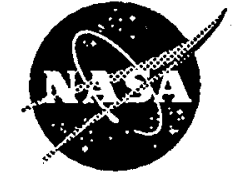

National Aeronautics and Space Administration

$$
\begin{aligned}
& \text { (NASA-TM-106820) PULSEO LASER } \\
& \text { ILLUMINATION OF PHOTOVOLTAIC CELLS } \\
& \text { (NASA. LeWIS Research Center) } 6 \text { P }
\end{aligned}
$$

N95-18572

Unclas 


\title{
PULSED LASER ILLUMINATION OF PHOTOVOLTAIC CELLS
}

\author{
Jane A. Yater† \\ NASA Lewis Research Center, Cleveland, Ohio 44135 \\ Roland A. Lowe \\ Kent State University, Kent, Ohio 44242 \\ Phillip P. Jenkins and Geoffrey A. Landis \\ NYMA, Inc., Brookpark, OH 44142
}

\begin{abstract}
In future space missions, free electron lasers (FEL) may be used to illuminate photovoltaic receivers to provide remote power. Both the radio-frequency (RF) and induction FEL produce pulsed rather than continuous output. In this work, we investigate cell response to pulsed laser light which simulates the RF FEL format. The results indicate that if the pulse repetition is high, cell efficiencies are only slightly reduced compared to constant illumination at the same wavelength. The frequency response of the cells is weak, with both voltage and current outputs essentially dc in nature. Comparison with previous experiments indicates that the RF FEL pulse format yields more efficient photovoltaic conversion than does an induction FEL format.
\end{abstract}

\section{INTRODUCTION}

The use of high power lasers has been proposed for beaming power to remote photovoltaic (PV) arrays in space. Power beaming during eclipse would eliminate the need for batteries on satellites in Geosynchronous Earth Orbit, thus reducing the mass of the satellite power system [1]. Night operation of a moon base could also be facilitated through earth-based laser illumination of PV arrays [2]. Photovoltaics can have very high efficiencies under monochromatic illumination compared to solar light [3], creating another advantage for laser power beaming. Many issues are involved in designing an appropriate laser and optical system $[1,4]$ and will influence the ultimate selection of lasers and cell materials.

The free electron laser (FEL) is an attractive choice for laser power beaming as it produces megawatts of power. It is also tunable to wavelengths appropriate for atmospheric transmission as well as for solar cell requirements. The two proposed FEL designs both produce pulses of light with high power rather than continuous output. The induction FEL [5] operates in the $\mathrm{kHz}$ frequency range, with pulse widths on the order of 10 ns. The RF FEL operates at $\mathrm{MHz}$ frequencies, producing pulses 5 to 40 ps wide [6]. While the average laser power reaching the cell must be sufficient to generate the required output power, the peak pulse power will be

$\uparrow$ National Research Council-NASA Research Associate at Lewis Research Center. hundreds or thousands of times higher than the average level.

The response of the photovoltaic receiver to the input pulses depends on the minority-carrier lifetime of the solar cell material [7]. When the pulses arrive in rapid succession relative to the lifetime, the cells effectively see the input as a continuous source. However, for pulse separations greater than the minority-carrier lifetime, the cell must respond to the peak power of each pulse. In Si cells, lifetimes range from 10 to $100 \mu \mathrm{s}$, while radiation damage can lower the value to $1 \mu \mathrm{s}$. Direct bandgap semiconductors such as $\mathrm{GaAs}$ have a much shorter minority-carrier lifetime, in the range of 10 to $100 \mathrm{~ns}$ [8]. Hence, the ability to convert FEL pulses to power depends on both the laser format and the cells being used.

Other experimental studies $[9,10]$ and $1-D$ computer simulations [11] have focused on the induction FEL format. Cell efficiencies are significantly reduced, especially for direct bandgap semiconductors. To successfully utilize the induction FEL, cell arrays must be designed that minimize series resistance and avoid LC oscillations. In this work, we investigate the response of conventional PV cells to laser light with the RF FEL format. Using a laser with pulse separations of about $10 \mathrm{~ns}$, we expect the cells to respond to the average illumination power. Results are compared with a previous study where a coppervapor laser was used to simulate the induction FEL pulse format [9].

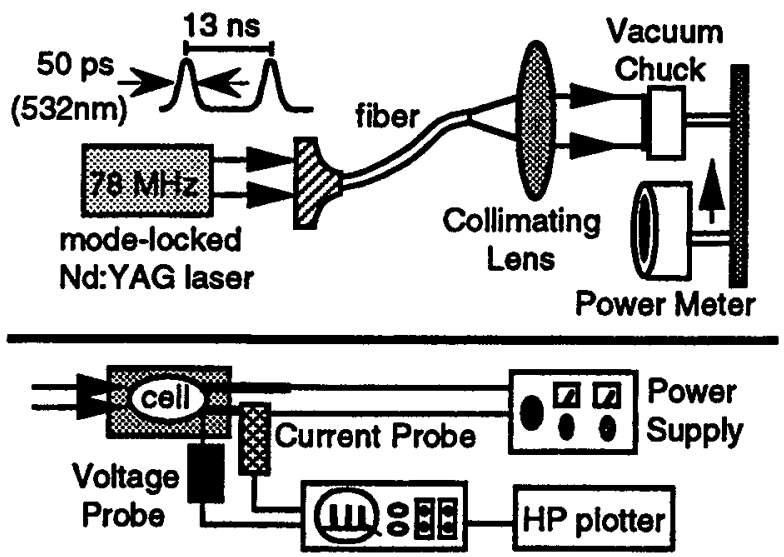

Fig. 1. Experimental apparatus. 

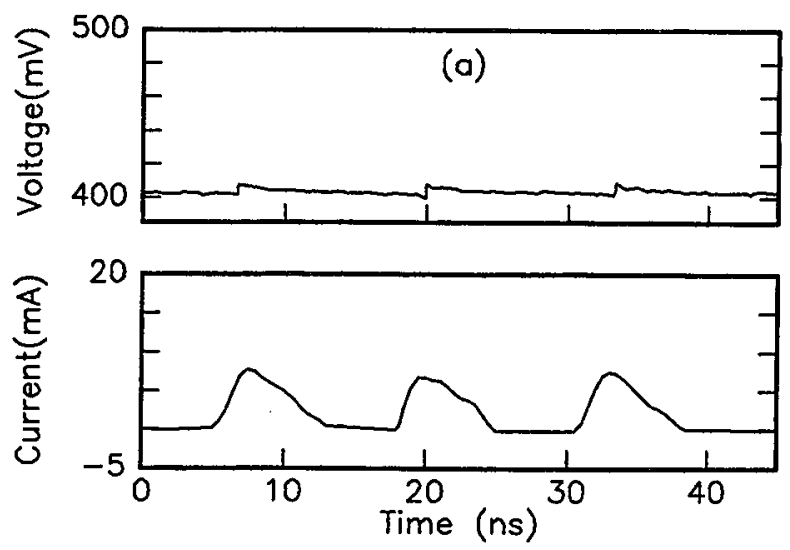

Fig. 2. Voltage and current waveforms for 10 a) RF FEL format, laser intensity 425

\section{EXPERIMENTAL PROCEDURE}

A Coherent Antares mode-locked Nd:YAG laser with 50 ps pulses at a frequency of $78 \mathrm{MHz}$ simulates the output of an RF FEL. Although typical RF FEL pulse widths may be significantly lower, since the 50 ps pulse width is well below the photovoltaic minority carrier storage time, the output is not expected to be very sensitive to the pulse width. The duty cycle of the laser, with pulses separated by $13 \mathrm{~ns}$, is $1: 260$. The peak power per pulse is therefore 260 times higher than the average laser power. In contrast, the copper-vapor laser used in the previous induction-format experiment produced pulses 38 ns wide and spaced $116 \mu \mathrm{s}$ apart, with a significantly lower duty cycle of $1: 3000$.

As depicted in Fig. 1, the laser is focused by a microscope objective into a $300 \mu \mathrm{m}$ optical fiber and collimated upon exiting the fiber. The fiber serves to homogenize the beam to produce a uniform intensity distribution across the cell. PV cells are mounted on an electrically-isolated vacuum chuck which moves on a rail normal to the optical path. A calibrated power meter, also mounted on the rail, is moved into the laser path to measure the time averaged power. The spatial uniformity of the beam over the area of the cells is within $10 \%$.

The frequency-doubled $532 \mathrm{~nm}$ wavelength is used to illuminate $\mathrm{Si}, \mathrm{GaAs}, \mathrm{CulnSe} \mathrm{e}_{2}$ (CIS) and $\mathrm{GaSb}$ solar cells, many of which were also tested in the induction FEL experiment [9]. Use of the $532 \mathrm{~nm}$ wavelength facilitates comparison with the $511 \mathrm{~nm}$ copper-vapor laser. Direct and indirect bandgap materials are included in order to examine the dependence of cell efficiency on minoritycarrier lifetime. All are planar cells, except for several $\mathrm{Si}$ and the GaSb concentrator cells. Since concentrator cells are designed to respond to high illumination intensities and peak currents, they may be more efficient in converting high power laser pulses.

The cells are tested at average illumination intensities between $4 \mathrm{~mW} / \mathrm{cm}^{2}$ and $425 \mathrm{~mW} / \mathrm{cm}^{2}$. The average DC output power $\left(P_{\text {out }}=I_{\text {out }} \times V_{\text {bias }}\right.$ ) is determined by applying a constant DC voltage across the cell with a variable bipolar power supply that can sink and source current. The average DC current is measured with a digital ammeter and is averaged over several hundred
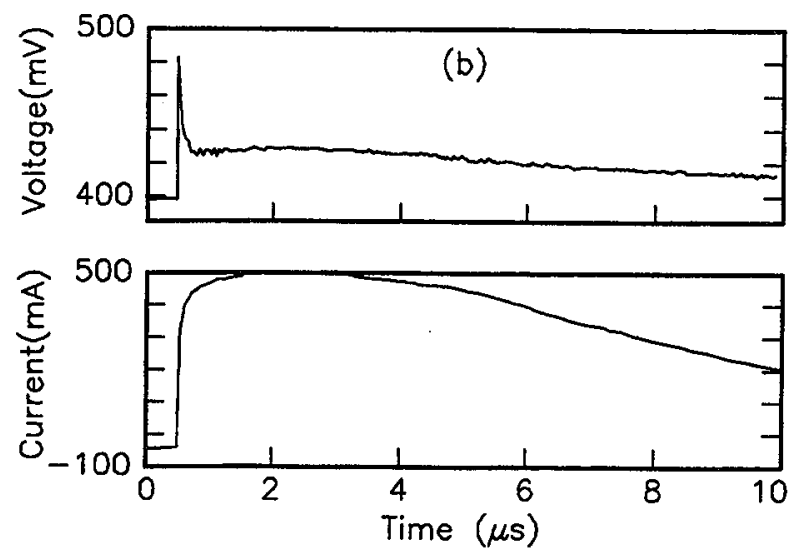

$\Omega-\mathrm{cm}$ Si concentrator cell biased near $400 \mathrm{mV}$. $\mathrm{mW} / \mathrm{cm}^{2}$. b) Induction FEL format, $279 \mathrm{~mW} / \mathrm{cm}^{2}$.

laser pulses. The conversion efficiency is calculated at the maximum power point using the relation

$$
\eta=\frac{\mathrm{P}_{\text {out }}}{\mathrm{P}_{\text {in }} \mathrm{A}}
$$

where $A$ is the total cell area, $P_{\text {in }}$ is the average incident laser power density and $P_{\text {out }}$ is the output power. The time dependence of the cell voltage and current is measured using a Tektronix 11802 digital sampling oscilloscope equipped with a $200 \mathrm{MHz}$ inductive current pickup and a $3.5 \mathrm{GHz}$ high-impedance sampling head.

\section{RESULTS}

The voltage waveform observed on the oscilloscope traces the time evolution of the bias voltage, which is maintained at a nominally constant level through feedback control. However, large current transients can interact with the inductance of the output wiring to induce voltage transients. Fig. $2 a$ shows voltage and current waveforms for a Si concentrator cell illuminated with $\mathrm{Nd}$ :YAG pulses at $425 \mathrm{~mW} / \mathrm{cm}^{2}$. For an applied bias of $400 \mathrm{mV}$, the resultant voltage waveform is essentially a DC signal. A small, sawtoothed AC component repeats every 13 ns. The corresponding current waveform is also nearly flat, with $10 \mathrm{~mA}$ current transients coinciding with the laser pulses. Similar behavior is exhibited by all the cells tested. The AC signal is largest at short-circuit conditions and under high laser intensities. At the maximum power point where cells are generally operated, such as in Fig. 2a, the transient response is almost negligible.

In contrast, Fig. $2 b$ shows the frequency response for the same cell and bias voltage, but illuminated at $279 \mathrm{~mW} / \mathrm{cm}^{2}$ by the copper-vapor laser[9]. The voltage rises in a spike as a laser pulse hits, slowly decaying over tens of microseconds to the DC bias level. The current transient of over half an amp decays equally slowly, as carriers diffuse to the depletion region. Such a cell output can hardly be maintained at a constant DC level. The response to the induction-format pulses varied considerably from cell to cell, with the most dramatic LC oscillations occuring with the GaAs concentrator cells [9]. However, every cell exhibited a strong $A C$ response and a corresponding reduction in conversion efficiency. The 

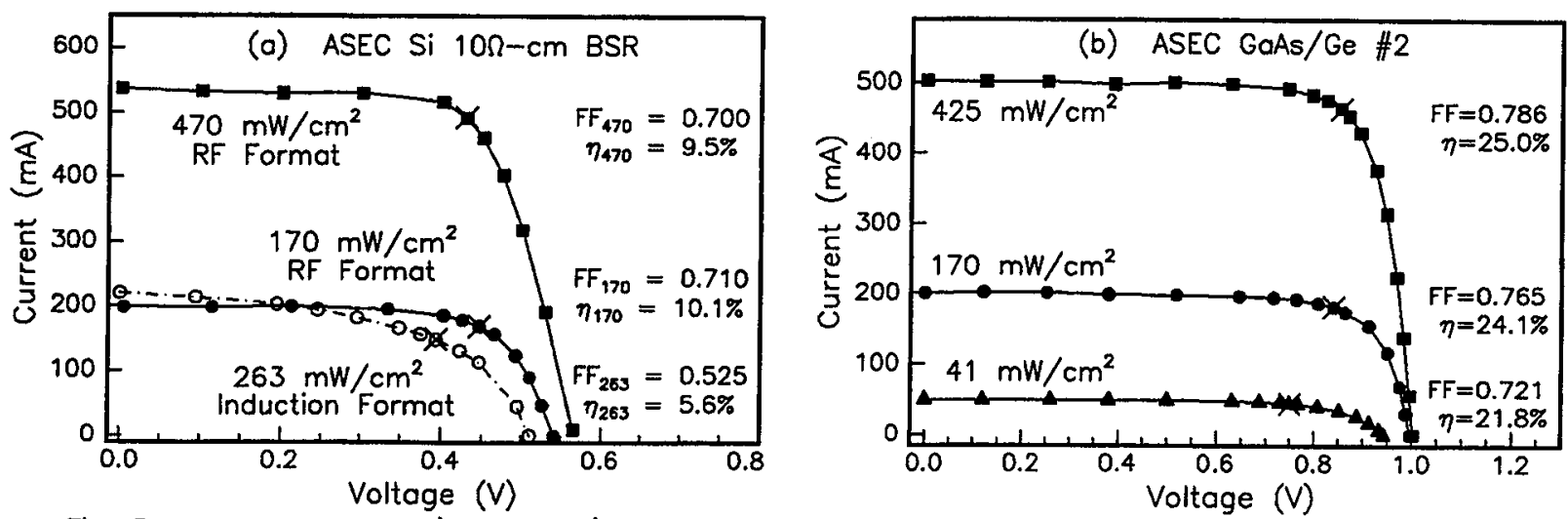

Fig. 3. $1-V$ Curves for a) $\mathrm{Si}$ and b) GaAs planar cells. The fill factor and efficiencies are shown for each curve. The maximum power point is marked with an $X$.

RF-type pulses produce a relatively flat $A C$ response and, as the data will show, good efficiencies.

Fig. 3a shows current-voltage curves for a $10 \Omega$-cm planar Si cell illuminated with both the RF (Nd:YAG) and induction (copper-vapor) type pulses. While the laser wavelength is comparable, the incident intensity is not identical. However, the cell performs better at $170 \mathrm{~mW} / \mathrm{cm}^{2}$ under the RF-simulated pulses than at the higher average power of $263 \mathrm{~mW} / \mathrm{cm}^{2}$ with the induction pulses. Both the fill factor and efficiency are significantly better, while $J_{s c}$ is comparable for both cases. The $\mathrm{Si}$ cell is able to convert the incoming Nd:YAG pulses more efficiently than the copper-vapor pulses, as already indicated by the frequency response. Even for Nd:YAG pulses at $470 \mathrm{~mW} / \mathrm{cm}^{2}$ (peak power $=800$ suns), where series resistance limiting of the current might cause deterioration of the cell performance, the fill factor and efficiency are essentially constant.

Comparisons of direct bandgap cells illuminated with both pulse formats, though not shown here, are even more striking. The cells perform well under the Nd:YAG illumination (although the $532 \mathrm{~nm}$ wavelength is far from optimal, especially for GaSb and CIS), as can be seen in the I-V curves of a typical GaAs cell shown in Fig. 3b. In contrast, efficiencies are exceedingly low for the coppervapor pulse experiments. $J_{s c}$ is several milliamps for the induction case but hundreds of milliamps under RF pulse conditions at comparable average intensities.

Efficiencies, calculated at the maximum power point, are compiled in Table 1 for AM0, CW argon-ion laser illumination ( $514 \mathrm{~nm})$, and pulsed illumination using both the Nd:YAG (532 $\mathrm{nm})$ and copper-vapor $(511 \mathrm{~nm})$ laser pulses. Efficiencies for the Si and GaAs cells tend to be a bit higher under monochromatic $\mathrm{CW}$ light than under the solar spectrum, an effect which would be even more noticeable at the optimum wavelength of each semiconductor material. A comparison of results from the $\mathbf{5 3 2}$ $\mathrm{nm}$ pulses and the $514 \mathrm{~nm}$ continuous illumination, both at $170 \mathrm{~mW} / \mathrm{cm}^{2}$, shows that the pulsed laser efficiency is slightly lower for the planar cells but higher for the concentrator cells. However, while the cell efficiency remains $70 \%$ to $99 \%$ of the $C W$ value using RF formatted pulses, the induction-type pulses cause a more extreme performance degradation. Si cells drop further in efficiency, while direct bandgap efficiencies fall to almost zero.

\begin{tabular}{|c|c|c|c|c|}
\hline & AM0 & $\begin{array}{c}\mathrm{cw} \\
514 \mathrm{~nm}\end{array}$ & $\begin{array}{l}\text { pulsed } \\
532 \mathrm{~nm}\end{array}$ & $\begin{array}{l}\text { pulsed } \\
511 \mathrm{~nm}\end{array}$ \\
\hline Intensity $\left(\mathrm{mW} / \mathrm{cm}^{2}\right)$ & 137 & 170 & 170 & 250 \\
\hline & \multicolumn{4}{|c|}{ cell efficiency, \% } \\
\hline \multicolumn{5}{|l|}{ Silicon } \\
\hline ASEC \#10 & 15 & & 13.3 & \\
\hline ASEC $10 \Omega$-cm BSR & 11.0 & 14.5 & 10.1 & 5.6 \\
\hline ASEC $0.2 \Omega-\mathrm{cm}$ & 15.6 & 19.0 & 14.5 & 7.2 \\
\hline MSFC ATM & 10.4 & 12.6 & 10.8 & \\
\hline ASEC (rad. damage) & 10.5 & $\overline{13.9}$ & 13.4 & 1.9 \\
\hline ASEC planar string & 11.1 & & 7.5 & \\
\hline Sunpower HECO (c) & 17.2 & & 19.2 & \\
\hline ASEC $10 \Omega-\mathrm{cm}(\mathrm{c})$ & 13.0 & 13.7 & 15.3 & 7.6 \\
\hline ASEC $0.15 \Omega-\mathrm{cm}(\mathrm{c})$ & 15.2 & 15.3 & 19.0 & $\overline{12.1}$ \\
\hline \multicolumn{5}{|l|}{ GaAs } \\
\hline Varian & 17.2 & 29.0 & 20.5 & 0.15 \\
\hline ASEC Mantec & 16.5 & 28.3 & 23.0 & \\
\hline ASEC \#2 & 17.5 & & 24.1 & \\
\hline Kopin Super (c) & 20.7 & 26.6 & & 1.3 \\
\hline \multicolumn{5}{|l|}{$\| I-V \mid$} \\
\hline Boeing GaSb (c) & 5.8 & 1.26 & 2.9 & 0.25 \\
\hline Boeing CIS & 8.2 & 5.5 & 5.3 & 0.01 \\
\hline
\end{tabular}

Table 1. Cell efficiency for different illumination conditions. Concentrator cells are denoted by (c). Laser intensity is average value.

The dependence of efficiency on average Nd:YAG laser power is plotted in Fig. 4 for representative cells. The average laser power levels of $425,170,41$ and 4 $\mathrm{mW} / \mathrm{cm}^{2}$ correspond to approximately $3.1,1.25,0.3$ and 0.03 suns, respectively, with peak powers of 810,325 , 80 and 8 suns. Some variation in efficiency with laser power is evident, with a maximum tending to occur at $170 \mathrm{~mW} / \mathrm{cm}^{2}$. However, the data at $425 \mathrm{~mW} / \mathrm{cm}^{2}$ show no sign of current saturation due to series resistance limiting at such high peak pulse powers, and the fill factors remain constant. Previous results with the induction formatted laser indicated that significant current saturation occurred at the highest laser intensities, where the peak 


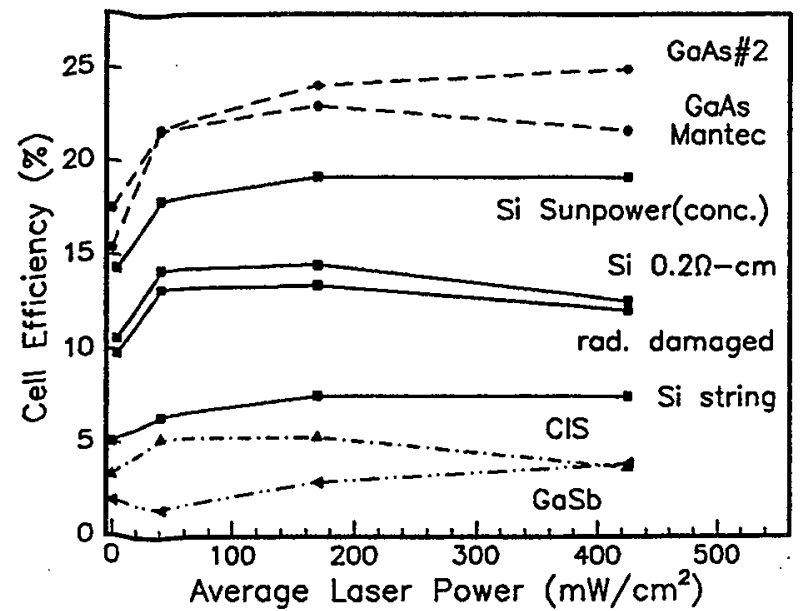

Fig. 4. Efficiency as a function of Nd:YAG loser power.

power increased to 6000 suns.

\section{DISCUSSION}

As noted previously, the efficiencies tabulated in this paper do not represent the peak values expected for laser wavelengths matched to the PV bandgap. The $532 \mathrm{~nm}$ light used in this experiment is chosen so that previous results can be compared and trends noted. The wavelength of peak monochromatic efficiency for $\mathrm{Si}$ is about $950 \mathrm{~nm}$ (shorter for damaged material), $850 \mathrm{~nm}$ for GaAs, 1600 $\mathrm{nm}$ for $\mathrm{GaSb}$ and $1000 \mathrm{~nm}$ for CIS. Efficiency corrections can be estimated by the ratio of the wavelengths [1]

$$
\frac{\eta\left(\lambda_{\text {peak }}\right)}{\eta\left(\lambda_{532 \mathrm{~nm}}\right)}=\frac{\lambda_{\text {peak }}}{\lambda_{532 \mathrm{~nm}}} \times \frac{Q E\left(\lambda_{\text {peak }}\right)}{Q E\left(\lambda_{532 \mathrm{~nm}}\right)}
$$

The wavelength term simply describes the inverse proportionality between incident laser power and wavelength. The quantum efficiency term is essentially equal to 1 , assuming that quantum efficiency, $Q E$, is nearly constant over the range of interest below the bandgap (as confirmed by measurements of external quantum yield).

For the $532 \mathrm{~nm}$ Nd:YAG laser pulses, no substantial difference in efficiency is evident between the various materials, with all planar cells performing at $70 \%$ to $99 \%$ of the $C W$ level. The minority-carrier lifetime, significantly shorter for the direct bandgap semiconductors than for $\mathrm{Si}$, does not limit the ability of the cells to respond to the high power pulses. If the cells actually see peak currents 260 times larger than the average current (based on the laser duty cycle), then every cell tested should display current saturation. Saturation is not observed, however, indicating approximately continuous wave illumination conditions. The Si concentrator cells, designed to respond to higher current densities than planar cells, exhibit a modest increase in efficiency under the RF-type laser pulses. Despite temporal stretching of the incident pulse due to minority-carrier diffusion, carrier concentrations rise above the average value as each pulse arrives. Concentrator cells are better able to collect these carriers than are the planar cells, as the results confirm. All the PV cells, however, convert the incident laser pulses to nearly $D C$ output with little loss relative to $C W$ laser results.

\section{CONCLUSIONS}

Experimental results indicate that the conversion efficiency of conventional PV cells illuminated with $\mathrm{MHz}$ frequency laser pulses is not reduced significantly. The $532 \mathrm{~nm}$ wavelength of a mode-locked $\mathrm{Nd}$ :YAG laser is used to simulate the RF FEL pulse format. The resultant cell performance is improved compared to previous results using a copper-vapor laser to simulate the induction FEL format. Direct bandgap cells exhibit the most significant enhancement in cell efficiency for incident laser intensities up to $425 \mathrm{~mW} / \mathrm{cm}^{2}$. The $A C$ frequency response of the cells to the short pulses is weak, and time averaged efficiencies are comparable to those under CW illumination conditions. Because the pulse separation is as short as the minority carrier lifetime, the cells respond as if the incident illumination is quasi-continuous in nature.

\section{REFERENCES}

[1] G.A. Landis, "Photovoltaic Receivers for Laser Beamed Power in Space". Twenty Second IEEE PVSC, 1991, pp. 1494-1502.

[2] G.A. Landis et al., "Photovoltaic Power for a Lunar Base", Acta Astron., 22, 1990, pp. 197-203.

[3] L.C. Olsen et al., "High Efficiency Monochromatic GaAs Solar Cells", Twenty Second IEEE PVSC, 1991, pp. 419-424.

[4] H. Weichel, Laser Beam Propagation in the Atmosphere, SPIE Optical Engineering Press, TT-3, Bellingham, WA, 1990.

[5] E.T. Scharlemann, "FEL Design Parameters and Device Tolerance", Review of SELENE FY91 Program Results and FY92 Program Kickoff, NASA Marshall Spaceflight Center, Dec. 10-11, IV-23.

[6] R. Burke et al., "Laser Power Beaming Applications and Technology", Laser Power Beaming. SPIE Conf. Proceedings Vol. 2161, 1994, p. 38.

[7] B.H. Rose, "Minority Carrier Lifetime Measurements on Si Solar Cells Using $I_{s c}$ and V $V_{o c}$ Transient Decay", IEEE Trans. Electron Dev., ED-31, 1984, pp. 559-565.

[8] R.K. Ahrenkiel, D.J. Dunlavy, and T. Hanak, "Photoluminescence Lifetime in Heterojunctions", Solar Cells, 24, 1988, pp. 339-352.

[9] R. Lowe, G.A. Landis, and P. Jenkins, "The Efficiency of Photovoltaic Cells Exposed to Pulsed Laser Light", Twelveth SPRAT Conference, NASA CP 3210, 1992, pp. 129-146.

[10] D. Willowby et al., "Response of Silicon Solar Cell to Pulsed Laser Illumination", Twelveth SPRAT Conference, NASA CP 3210, 1992, pp. 147-154.

[11] R.K. Jain and G.A. Landis, "Transient Response of GaAs and Si Solar Cells Under Laser Pulse". First World Conference on Photovoltaic Energy Conversion, Dec. 5-9, 1994, Waikoloa, HI. 


\section{REPORT DOCUMENTATION PAGE}

Public reporting burden for this collection of information is estimated to average 1 hour per response, including the time for reviewing instructions, searching existing data sources, gathering and maintaining the data needed, and completing and reviewing the collection of intormation. Send comments regarding this burden estimate or any other aspect of this collection of information, including suggestions for reducing this burden, to Washington Headquarters Services, Directorate for Information Cperations and Reports, Davis Highway, Suite 1204, Arlington, VA 22202-4302, and to the Office of Management and Budget, Paperwork Reduction Project (0704-0188), Washington, DC 20503.
1. AGENCY USE ONLY (Leave blank)
2. REPORT DATE
January 1995
3. REPORT TYPE AND DATES COVERED
Technical Memorandum

4. TITLE AND SUBTITLE

Pulsed Laser Illumination of Photovoltaic Cells

6. AUTHOR(S)

Jane A. Yater, Roland A. Lowe, Phillip P. Jenkins and Geoffrey A. Landis

WU-233-01-OA

\section{PERFORMING ORGANIZATION NAME(S) AND ADDRESS(ES)}

National Aeronautics and Space Administration

Lewis Research Center

Cleveland, Ohio 44135-3191
8. PERFORMING ORGANIZATION REPORT NUMBER

E-9362

9. SPONSORING/MONITORING AGENCY NAME(S) AND ADDRESS(ES)

10. SPONSORING/MONITORING AGENCY REPORT NUMBER

National Aeronautics and Space Administration

Washington, D.C. 20546-0001

NASA TM-106820

11. SUPPLEMENTARY NOTES

Prepared for the First World Conference on Photovoltaic Energy Conversion cosponsored by the IEEE, PVSEC-Japan and PVSEC-Europe, Waikoloa, Hawaii, December 5-9, 1994. Jane A. Yater, National Research Council-NASA Research Associate at Lewis Research Center; Roland A. Lowe, Kent State University, Kent, Ohio 44242 and NASA Resident Research Associate at Lewis Research Center; Phillip P. Jenkins and Geoffrey A. Landis, NYMA, Inc., Engineering Services Division, 2001 Aerospace Parkway, Brook Park, Ohio 44142. Responsible person, Jane A. Yater, organization code 5410, (216) 433-8485.

12a. DISTRIBUTION/AVAILABILITY STATEMENT

Unclassified-Unlimited

Subject Category 44

12b. DISTRIBUTION CODE

This publication is available from the NASA Center for Aerospace Information, (301) 621-0390.

13. ABSTRACT (Maximum 200 words)

In future space missions, free electron lasers (FEL) may be used to illuminate photovoltaic receivers to provide remote power. Both the radio-frequency (RF) and induction FEL produce pulsed rather than continuous output. In this work we investigate cell response to pulsed laser light which simulates the RF FEL format. The results indicate that if the pulse repetition is high, cell efficiencies are only slightly reduced compared to constant illumination at the same wavelength. The frequency response of the cells is weak, with both voltage and current outputs essentially dc in nature. Comparison with previous experiments indicates that the RF FEL pulse format yields more efficient photovoltaic conversion than does an induction FEL format.

14. SUBJECT TERMS

Solar cells; Pulsed illumination; Laser power beaming

15. NUMBER OF PAGES

06

16. PRICE CODE

$\mathrm{AO} 2$

\begin{tabular}{l|c}
\hline $\begin{array}{c}\text { 17. SECURTY CLASSIFICATION } \\
\text { OF REPORT }\end{array}$ & $\begin{array}{c}\text { 18. SECURITY CLASSIFICATION } \\
\text { OF THIS PAGE } \\
\text { Unclassified }\end{array}$ \\
\begin{tabular}{c} 
Unclassified \\
\hline
\end{tabular}
\end{tabular}

19. SECURITY CLASSIFICATION OF ABSTRACT Unclassified 